\title{
Produção de creme hidratante enriquecido com óleo essencial de alecrim obtido via extração enzimática fúngica
}

\author{
Production of moisturizing cream enriched with rosemary essential oil obtained via enzymatic
} fungal extraction

Producción de crema hidratante enriquecida con aceite esencial de romero obtenido mediante extracción fúngica enzimática

\author{
Ana Luiza Caíres Souza \\ ORCID: https://orcid.org/0000-0002-3782-0446 \\ Faculdade Independente do Nordeste, Brasil \\ E-mail: analuizacs2699@gmail.com \\ Camila Martins Nascimento \\ ORCID: https://orcid.org/0000-0001-5718-155X \\ Faculdade Independente do Nordeste, Brasil \\ E-mail: camilamartinsmv@gmail.com \\ Tayanne Andrade dos Santos \\ ORCID: https://orcid.org/0000-0002-7977-6308 \\ Faculdade Independente do Nordeste, Brasil \\ E-mail: tayanne.as@hotmail.com \\ Tatielle Pereira Silva \\ ORCID: https://orcid.org/0000-0002-8086-0574 \\ Faculdade Independente do Nordeste, Brasil \\ E-mail: tatielle@fainor.com.br
}

\begin{abstract}
Resumo
A extração de óleos essenciais de plantas aromáticas é um processo que apresenta consideráveis desvantagens como a utilização de equipamentos altamente custosos, elevada quantidade de solventes orgânicos com grande potencial de contaminação, além da necessidade de grande quantidade de matéria-prima para obtenção de uma pequena fração de óleo. Nesta perspectiva, é crescente o desenvolvimento de metodologias sustentáveis de investigação de produtos naturais, como os óleos essenciais, com o intuito de promover o aumento no rendimento de extração do óleo essencial, a redução no custo da produção e a ampliação na qualidade do mesmo. Assim, com o propósito de otimizar a extração do óleo essencial de Rosmarinus officinalis L., alcançando simultaneamente um maior rendimento e pureza do mesmo, esse trabalho teve como objetivo analisar a produção de creme hidratante a partir de óleo essencial de alecrim extraído pela aplicação de enzimas produzidas por fungos filamentosos do gênero Rhizopus sp. Os resultados evidenciaram que a partir da aplicação dos extratos multienzimáticos (EMB) alcançou-se uma otimização de 83,24\% na extração do óleo de alecrim, que obteve também os parâmetros físicos, químicos e organolépticos desejados e necessários de acordo com a legislação vigente. Além de que, desenvolveu-se uma formulação tópica cosmética com a adição do óleo essencial extraído que também atingiu as especificações e os padrões de qualidade exigidos pela Farmacopeia Brasileira.
\end{abstract}

Palavras-chave: Óleo essencial; Enzimas; Alecrim; Fungos filamentosos.

\begin{abstract}
The extraction of essential oils from aromatic plants is a process that presents considerable disadvantages such as the use of highly expensive equipment, high quantity of organic solvents with great potential for contamination, besides the need for a large quantity of raw material to obtain a small fraction of oil. In this perspective, the development of sustainable methodologies for the research of natural products, such as essential oils, with the purpose of promoting the increase in the yield of essential oil extraction, the reduction in the cost of production and the increase in its quality is growing. Thus, with the purpose of optimizing the extraction of the essential oil of Rosmarinus officinalis L., achieving simultaneously a greater yield and purity of the same, this work aimed to analyze the production of moisturizing cream from rosemary essential oil extracted by the application of enzymes produced by filamentous fungi of the genus Rhizopus sp. The results showed that from the application of multi-enzyme extracts (EMB) an optimization of $83.24 \%$ was reached in the extraction of rosemary oil, which also obtained the physical, chemical and organoleptic parameters desired and required according to the current legislation. In addition, a cosmetic topical formulation was developed with the addition of the extracted essential oil that also met the specifications and quality standards required by the Brazilian Pharmacopoeia.
\end{abstract}

Keywords: Essential oil; Enzymes; Rosemary; Filamentous fungi. 


\begin{abstract}
Resumen
La extracción de aceites esenciales de plantas aromáticas es un proceso que presenta considerables desventajas como el uso de equipos muy costosos, alta cantidad de disolventes orgánicos con gran potencial de contaminación, además de la necesidad de una gran cantidad de materia prima para obtener una pequeña fracción de aceite. En esta perspectiva, el desarrollo de metodologías sostenibles de investigación de productos naturales, como los aceites esenciales, con la intención de promover el aumento en el rendimiento de extracción del aceite esencial, la reducción en el coste de la producción y el aumento en la calidad del mismo es cada vez mayor. Así, con el fin de optimizar la extracción del aceite esencial de Rosmarinus officinalis L., logrando simultáneamente un mayor rendimiento y pureza del mismo, este trabajo tuvo como objetivo analizar la producción de crema hidratante a partir de aceite esencial de romero extraído mediante la aplicación de enzimas producidas por hongos filamentosos del género Rhizopus sp. Los resultados mostraron que a partir de la aplicación de extractos multienzimáticos (EMB) se alcanzó una optimización del 83,24\% en la extracción del aceite de romero, con lo que además se obtuvieron los parámetros físicos, químicos y organolépticos deseados y exigidos según la legislación vigente. Además, se desarrolló una formulación tópica cosmética con la adición del aceite esencial extraído que también alcanzó las especificaciones y estándares de calidad exigidos por la Farmacopea Brasileña.
\end{abstract}

Palabras clave: Aceite esencial; Enzimas; Rosemary; Hongos filamentosos.

\title{
1. Introdução
}

Atualmente, observando as necessidades e preocupações da sociedade em relação ao consumo, pode-se notar a tendência dos consumidores à procura de produtos de origem natural, principalmente aqueles com finalidades medicinais e estéticas (Migoto, 2018). Motivados pelo conhecimento em relação à saúde e pela consciência ambiental, é crescente o interesse dos consumidores acerca da composição dos produtos, dos métodos de produção e dos testes realizados (Martins et al., 2008).

Visto que as plantas com propriedades terapêuticas constituem fontes significativas de compostos bioativos, realça-se, a importância das plantas medicinais como alternativa para o desenvolvimento de produtos que atendam às características demandadas (Sarto-Zanusso, 2014) sendo constantemente empregadas em fórmulas farmacêuticas com o intuito de desenvolver terapias eficazes, seguras e menos agressivas (Martins et al., 2008). Nesta perspectiva, o desenvolvimento de metodologias sustentáveis de investigação de produtos naturais, como os óleos essenciais, é de grande proveito (Almeida et al., 2020). Em sua constituição natural, determinadas plantas dispõem de óleos essenciais - OE’s., que são amplamente definidos como um conjunto de substâncias voláteis e lipofílicas, comumente líquidos, com odor e cor característicos (Martins et al., 2008). A extração de óleos essenciais pode ser realizada por meio de diversos processos físicos e mecânicos, sendo a hidrodestilação, a extração por solventes orgânicos, a destilação a vapor e a prensagem a frio, os mais utilizados. Contudo, esses métodos apresentam consideráveis desvantagens como; equipamentos altamente custosos, elevada quantidade de solventes orgânicos que apresentam grande potencial de contaminação do óleo essencial, assim como as ceras e os pigmentos da matéria-prima geralmente adicionados (Reis, 2015). Assim, tem se destacado a utilização de enzimas em processos de extração de metabólitos de materiais vegetais, especificamente, os óleos essenciais (Reis, 2019).

A aplicação do tratamento enzimático otimiza a produtividade na obtenção dos OE's, pois a utilização das enzimas auxilia na degradação da parede celular dos vegetais favorecendo na retirada dos óleos (Reis, 2015). Desta forma, a extração enzimática exclui a utilização de solventes, ocasionando a redução do consumo de energia, e por conseguinte, os custos do processo (Santos, 2008). Para a produção de extratos multienzimáticos, tem sido muito empregada a FES - fermentação em estado sólido de biomassas. As biomassas mais aproveitadas na FES são os resíduos agroindustriais, que atuam como base sólida e ofertam nutrientes para o crescimento de microrganismos. Bactérias, leveduras e fungos podem ser utilizados com a finalidade de excreção enzimática, no entanto, os fungos filamentosos são os mais importantes microrganismos empregados (Reis, 2015; Santos, 2008).

Entre os óleos essenciais de maior relevância encontra-se o óleo de alecrim. Rosmarinus officinalis L., o alecrim, é uma planta pertencente à família Lamiaceae, nativa da região mediterrânea, muito evidenciada desde a antiguidade devido às suas particularidades medicinais, alimentícia e aromatizante (Peixoto et al., 2017). Conhecido mundialmente em razão de suas 
inúmeras indicações terapêuticas, com destaque às propriedades antioxidante, anti-inflamatória, cicatrizante, alopecia, antifúngica, antidepressiva, antibacteriana, antirreumática e antiespasmódica. Quimicamente, o OE é constituído basicamente por $\beta$-pineno, $\alpha$-pineno, 1,8-cineol, borneol, cânfora, limoneno, verbenona e acetato de bornila; em relação à concentração desses compostos ao depender do local de cultivo, da sazonalidade e de características inerentes à planta, podem ocorrer variações (Santos et al., 2020).

Ao decidir desenvolver uma formulação com óleos essenciais, é preciso adequar os excipientes farmacêuticos, a fim de que ações como solubilização, diluição, emulsificação, estabilização, conservação e coloração possibilitem a conquista de uma forma farmacêutica atraente, segura eficaz (Martins et al., 2008). Assim, diante das atividades terapêuticas do óleo essencial de alecrim, de sua relevante inserção na indústria farmacêutica e associada ao apelo do consumidor pela maior aplicação de constituintes naturais em produtos, sobretudo nos cosméticos, esta pesquisa apresenta como objetivo, analisar a viabilidade na extração enzimática do óleo essencial de alecrim tendo como finalidade empregá-lo na formulação de um creme hidratante.

\section{Metodologia}

O presente estudo utiliza-se da metodologia experimental, uma vez que se trata da produção de uma formulação cosmética hidratante contendo o óleo essencial de alecrim extraído, por sua vez, através da aplicação de enzimas produzidas por fungos filamentosos, até então um procedimento alternativo ao convencional, utilizando dos métodos propostos por Reis e pelo Guia de estabilidade de produtos Cosméticos, elaborado pela Agência Nacional de Vigilância Sanitária - ANVISA. A fim de facilitar a compreensão das etapas experimentais desta pesquisa, segue o fluxograma descrevendo de modo geral os estágios seguidos (Figura 1):

Figura 1 - Fluxograma da parte experimental.

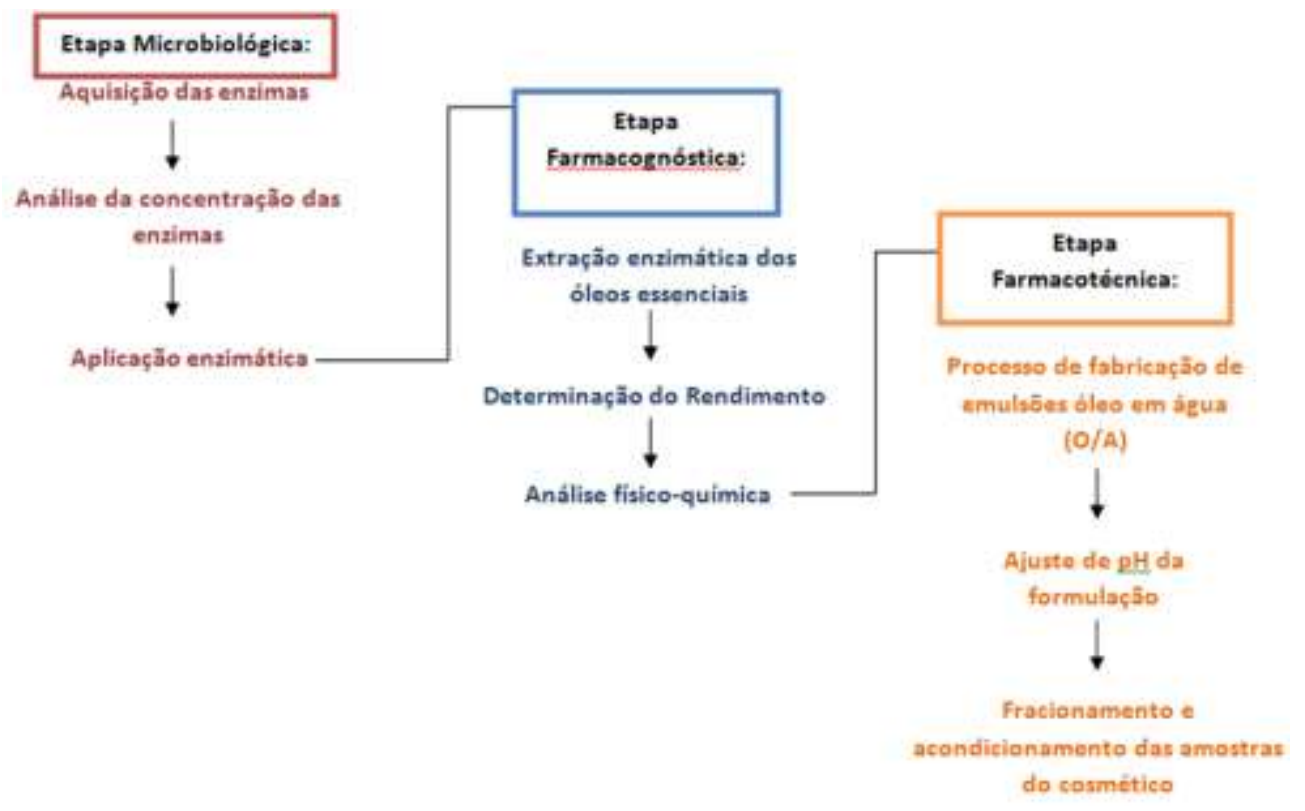

Fonte: Autores.

\subsection{Coleta do Material Vegetal para Obtenção dos Óleos Essenciais}

A matéria-prima vegetal utilizada neste projeto, as folhas de alecrim, foram coletadas manualmente pelas autoras em uma fazenda localizada no interior de Minas Gerais. 


\subsection{Obtenção e Preparação do farelo de café}

As amostras foram cedidas por indústrias de café da região Sudeste da Bahia. Após a higienização, colocaram-se os resíduos de café em estufa de secagem (QUIMIS*) por $65^{\circ} \mathrm{C}$ durante 15 minutos, e posteriormente realizou-se o processo de secagem por 24h (Reis, 2015).

\subsection{Preparo do inóculo}

Foram utilizados neste trabalho o fungo filamentoso Rhizopus microsporus registrado 011240290N (Figura 2), cedidos pela Fundação Oswaldo Cruz- FIOCRUZ-Rio de Janeiro. A fim de se obter os inóculos, os microrganismos foram cultivados em meio sólido Potato Dextrose Agar $(20 \mathrm{~mL})$ utilizando placas de Petri. Sendo incubados por 7 dias em estufa a $30^{\circ} \mathrm{C}$, para que se obtivesse o crescimento desejado (Reis, 2015).

Figura 2 - Fungo filamentoso Rhizopus microsporus.

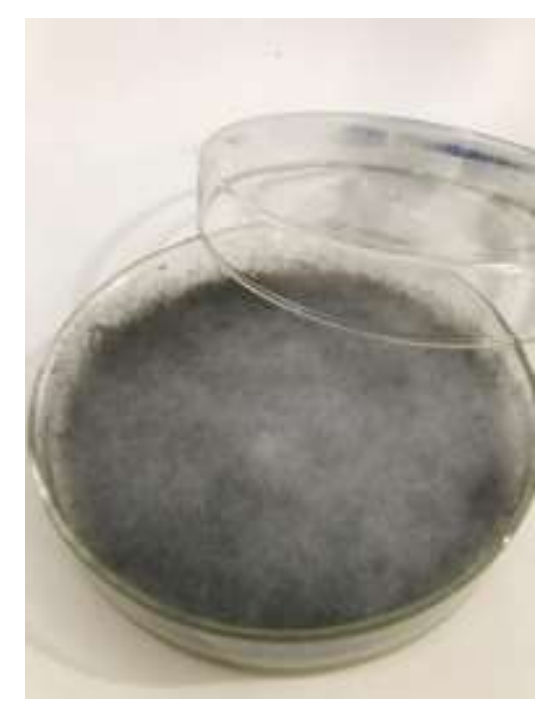

Fonte: Autores.

\subsection{Bioprocesso - FES}

Utilizou-se 7 erlenmeyers de $250 \mathrm{~mL}$ como biorreatores para o processo fermentativo tendo como meio de cultivo o farelo de café, sendo então pesados: $1=10,005 \mathrm{~g} ; 2=10,012 \mathrm{~g} ; 3=10,021 \mathrm{~g} ; 4=10,015 \mathrm{~g} ; 5=10,025 \mathrm{~g} ; 6=10,002 \mathrm{~g} ; 7=10,015 \mathrm{~g}$ da biomassa, submetendo-as à esterilização em autoclave a $121^{\circ} \mathrm{C}$ e $1,0 \mathrm{~atm}$ de pressão por 15 minutos. Posteriormente, foi realizado o resfriamento dos mesmos. As fermentações foram conduzidas em estufas bacteriológicas a $30^{\circ} \mathrm{C}$ durante 7 dias, sendo que a cada dia retirava-se um biorreator, a fim de se averiguar em qual prazo apresentaria maior potencial de enzimas (Reis, 2015).

\subsubsection{Obtenção do extrato multienzimáticos}

Para a obtenção dos extratos enzimáticos após o processo fermentativo do farelo de café, adicionou-se em cada biorreator $50 \mathrm{~mL}$ de solução tampão de acetato de sódio (pH 5,0 mM). Os extratos foram homogeneizados com auxílio de um bastão de vidro. A extração foi realizada por prensagem manual para a obtenção do extrato bruto enzimático, após isso o extrato foi utilizado para a dosagem das atividades enzimáticas (Reis, 2015). 


\subsection{Determinação da atividade enzimática}

A fim de se determinar a concentração enzimática dos extratos produzidos, os mesmos foram submetidos à leitura no espectrofotômetro tipo U2M (QUIMIS*). Adicionou-se: $100 \mu \mathrm{L}$ de CMC; $50 \mu \mathrm{L}$ do EMB (extrato multienzimático bruto); $150 \mu \mathrm{L}$ tampão acetato. Posteriormente, colocou-se o tubo em banho maria (com temperatura de $50{ }^{\circ} \mathrm{C}$ ). $\mathrm{O}$ branco obteve a mesma composição, com exceção do extrato, sendo assim foi adicionado $200 \mu \mathrm{L}$ do acetato.

\subsection{Extração do óleo}

A extração do óleo essencial foi realizada nos Laboratórios de Saúde de uma instituição de ensino superior privada no Sudoeste da Bahia. As amostras foram submetidas ao processo de extração por hidrodestilação usando um aparelho Clevenger. $\mathrm{O}$ tratamento com o extrato enzimático foi realizado durante 1 hora, a uma temperatura de $50^{\circ} \mathrm{C}$. Em paralelo, separou-se uma amostra para a realização do teste controle, onde a mesma quantidade de material vegetal foi submetida às mesmas condições de tratamento, porém somente com o tampão acetato. Após o tratamento, os balões foram acoplados ao aparelho de Clevenger, para posterior extração (Santos, 2008).

Figura 3 - Balão de fundo redondo com folhas de alecrim em solução.

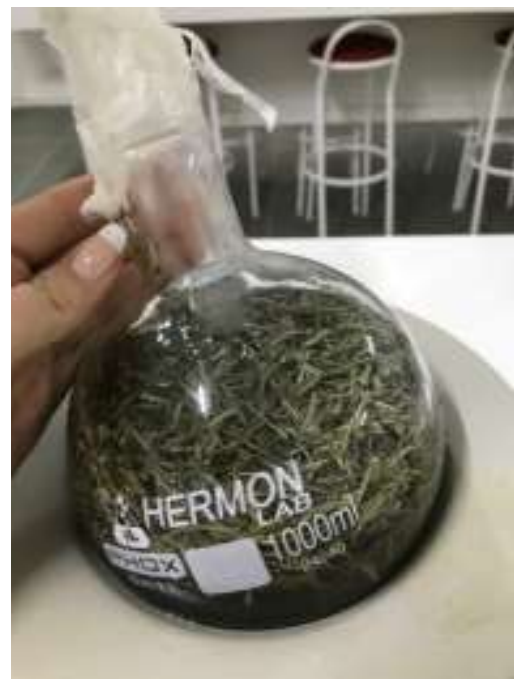

Fonte: Autores.

\subsubsection{Determinação do rendimento de óleo produzido}

O rendimento do óleo produzido foi determinado a partir da análise do tempo de extração e da quantidade extraída, realizando o comparativo com a literatura estudada.

\subsubsection{Análises}

Com o óleo essencial extraído realizou-se os ensaios organolépticos (aspecto, cor e odor) e físico-químicos (pH e densidade).

\subsection{Desenvolvimento da formulação tópica 1}

Para a preparação da formulação tópica foi aplicado o processo convencional de fabricação de emulsões óleo em água (O/A), denominado como técnica de inversão de fases. De inicio, a vaselina, componente da fase oleosa, foi pesada em um béquer. Em outro béquer, foi pesada e dissolvida a lanolina. Por fim, incorporou-se o óleo à fase oleosa sob agitação manual, mantendo o procedimento até que o sistema atingisse a consistência desejada. Utilizou-se na formulação 1, a composição na 
proporção de 50/50: vaselina + lanolina, sendo pesada quantidade suficiente para (q.s.p): vaselina= 5,1791g; lanolina= $5,0773 \mathrm{~g}$; óleo de alecrim=1,0307g (ANVISA, 2004).

\subsubsection{Desenvolvimento da formulação tópica 2}

Primeiramente, pesou-se 30g da formulação não iônica composta por fase aquosa: metilparabeno, propilenoglicol,

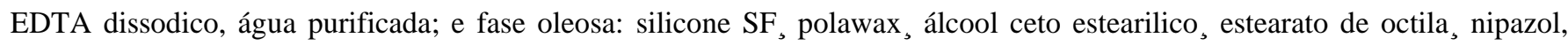
BHT; em seguida, realizou-se a incorporação do óleo de Rosmarinus officinalis L. (alecrim) na mesma, sendo a concentração de 1,0\%. Assim, incorporou-se o óleo à formulação, através de movimentos circulares sob agitação mecânica manual, a fim de que a formulação alcançasse a homogeneização adequada.

\subsubsection{Análises das formulações}

Realizaram-se posteriormente com a formulação produzida os ensaios organolépticos: aspecto, cor, odor; e físicoquímicos: pH e densidade (Silva, 2019; Pagnoca-Cardoso, 2008).

\section{Resultados}

\subsection{Determinação do período (em dias) de maior atividade enzimática nos extratos multienzimáticos brutos (EMB's)}

Com a finalidade de se averiguar em qual intervalo de tempo os extratos enzimáticos produzidos alcançariam o máximo teor de enzimas, os erlermeyers foram retirados dia a dia da estufa, no decorrer de sete dias, seguindo a metodologia proposta por Reis. Após isso, os mesmos foram submetidos à análise no espectrofotômetro (Tabela 1). Sendo que, após as leituras, a amostra 7 (retirada no sétimo dia) foi a que resultou em maior concentração enzimática, com valor médio de 0,540A e desvio padrão equivalente a 0,1245 .

\subsection{Extração de óleo essencial de alecrim com tratamento enzimático}

Inicialmente, utilizou-se $30 \mathrm{~g}$ do material vegetal (alecrim), com a adição de $50 \mathrm{~mL}$ de EMB, juntamente com $900 \mathrm{~mL}$ de água destilada e $50 \mathrm{~mL}$ do tampão (acetato de sódio) em um balão de fundo redondo; levando o mesmo para banho maria $\left(50^{\circ} \mathrm{C}\right)$ por 1 hora. Paralelo a isso, a amostra sem adição do extrato enzimático (*branco) foi composta por 30g de alecrim, $900 \mathrm{~mL}$ de água e $100 \mathrm{~mL}$ do tampão. Assim, ambas foram submetidas ao processo de hidrodestilação no aparelho Clevenger.

Tabela 1 - Determinação da atividade enzimática nos EMB's segundo leitura no espectrofotômetro U2M.

\begin{tabular}{|c|c|c|c|c|}
\hline Amostra & Leitura 1 & \multicolumn{1}{c}{ Leitura 2 } & \multicolumn{1}{c}{ Leitura 3 } & Média \\
\hline Branco & $0.069 \mathrm{~A}$ & ---- & $0.164 \mathrm{~A}$ & $0.114 \mathrm{~A}$ \\
\hline Dia 1 & $0.085 \mathrm{~A}$ & $0.093 \mathrm{~A}$ & $0.222 \mathrm{~A}$ & $0,185 \mathrm{~A}$ \\
\hline Dia 2 & $0.178 \mathrm{~A}$ & $0.156 \mathrm{~A}$ & $0.206 \mathrm{~A}$ & $0.223 \mathrm{~A}$ \\
\hline Dia 3 & $0.261 \mathrm{~A}$ & $0.202 \mathrm{~A}$ & $0.339 \mathrm{~A}$ & $0.374 \mathrm{~A}$ \\
\hline Dia 4 & $0.366 \mathrm{~A}$ & $0.418 \mathrm{~A}$ & $0.489 \mathrm{~A}$ & $0,394 \mathrm{~A}$ \\
\hline Dia 5 & $0.325 \mathrm{~A}$ & $0.369 \mathrm{~A}$ & $0.618 \mathrm{~A}$ & $0,536 \mathrm{~A}$ \\
\hline Dia 6 & $0.561 \mathrm{~A}$ & $0.431 \mathrm{~A}$ & $\mathbf{0 . 4 3 3 A}$ & $\mathbf{0 , 5 4 0 A}$ \\
\hline
\end{tabular}

Fonte: Autores.

\subsection{Rendimento da extração de óleo essencial de alecrim com e sem tratamento enzimático.}

Após decorrer 5 horas do processo de extração, comparou-se a massa obtida entre os dois. Sendo que, a amostra incorporada ao extrato atingiu o peso de $0,645 \mathrm{~g}$, enquanto que o "branco" obteve $0,352 \mathrm{~g}$. Houve assim um aumento considerável de $83,24 \%$ no rendimento do óleo (Tabela 2). 
Tabela 2 - Aumento da massa de óleo essencial de alecrim, após 5 horas de extração, utilizando extrato multienzimático obtido do farelo de café.

\begin{tabular}{cccccccc}
\hline Ensaios & $\mathbf{T}_{\mathbf{e}}$ & $\mathbf{T}_{\mathbf{h}}$ & $\mathbf{V}(\mathbf{m L})$ & $\mathbf{M}(\mathbf{g})$ & $*$ MSE & MCE & AOC (\%) \\
\hline $\mathbf{1}$ & $50^{\circ} \mathrm{C}$ & $5 \mathrm{~h}$ & $50 \mathrm{~mL}$ & $30 \mathrm{~g}$ & $0,352 \mathrm{~g}$ & $0,645 \mathrm{~g}$ & 83,24 \\
\hline
\end{tabular}

$\mathrm{Te}=$ temperatura $/ \mathrm{Th}=$ tempo $/ \mathrm{V}=$ volume de extrato/ $\mathrm{M}(\mathrm{g})=$ massa de matéria vegetal/ MSE=Massa de óleo extraído sem enzimas / $\mathrm{MCE}=$ Massa de óleo extraído com enzimas/ AOE = Aumento da massa do óleo extraído (\%). Fonte: Autores.

\subsection{Ensaios organolépticos e físico-químicos com o óleo extraído}

O óleo extraído com o auxílio da tecnologia enzimática foi subordinado aos testes físico-químicos de pH e densidade. Sendo que ele obteve $\mathrm{pH}$ de 4,8 e densidade de $0,86 \mathrm{~g} / \mathrm{mL}$. Em relação às características organolépticas, o óleo de alecrim apresentou aspecto líquido, de cor levemente amarelada e odor forte característico, apresentando conformidade com as orientações da Farmacopéia Brasileira.

\subsection{Desenvolvimento das formulações}

Visando desenvolver um creme que atingisse características ideais e agradáveis, inicialmente foi consultada na literatura a composição adequada para a formulação, uma vez que deveriam ser consideradas as características físico-químicas tanto do óleo essencial, quanto dos excipientes das bases. Desse modo, desenvolveram-se duas formulações distintas (tabela 3 e 4).

Tabela 3 - Componentes e Funções da Formulação Teste 1.

\begin{tabular}{ccc}
\hline FASES & COMPONENTES & FUNÇÃO \\
\hline OLEOSA: & Vaselina & Excipiente hidrofóbico \\
& Lanolina & Emulsificante \\
\hline
\end{tabular}

Fonte: própria da pesquisa.

Tabela 4 - Componentes e Funções da Formulação Teste 2.

\begin{tabular}{|c|c|c|}
\hline FASES & COMPONENTES & FUNÇÃAO \\
\hline AQUOSA: & $\begin{array}{l}\text { Metilparabeno } \\
\text { Propilenoglicol } \\
\text { EDTA dissodico } \\
\text { Água purificada }\end{array}$ & $\begin{array}{l}\text { Conservante } \\
\text { Umectante } \\
\text { Quelante } \\
\text { Veículo }\end{array}$ \\
\hline OLEOSA: & $\begin{array}{c}\text { Silicone SF } \\
\text { Polawax } \\
\text { Álcool ceto estearilico } \\
\text { Estearato de octila } \\
\text { Nipazol } \\
\text { BHT }\end{array}$ & $\begin{array}{c}\text { Emulsificante } \\
\text { Emulsificante } \\
\text { Emoliente } \\
\text { Emoliente } \\
\text { Conservante } \\
\text { Antioxidante }\end{array}$ \\
\hline
\end{tabular}

Fonte: Autores.

\subsubsection{Análises das formulações desenvolvidas}

Posteriormente, as fórmulas hidratantes criadas foram sucedidas aos testes físico-químicos de $\mathrm{pH}$ e densidade, onde a formulação 1 (figura 4) atingiu o pH de 5,0 e a densidade aparente de $1,9 \mathrm{~g} / \mathrm{cm}^{3}$; e a formulação 2 (figura 5) obteve $\mathrm{pH}$ de 4,88 
e densidade de $2 \mathrm{~g} / \mathrm{cm}^{3}$, estabelecendo uma grande similitude entre si. As mesmas também foram avaliadas quanto às suas características organolépticas- aspecto, cor e odor (Tabela 5). Caracterizando-se como formulações de pH ideais, no entanto, com uma densidade superior quando comparadas à outros cremes hidratantes (Silva, 2019; Pagnoca e Cardoso, 2008).

Tabela 5 - Características organolépticas, pH e densidade das formulações nos tempos 0 e 30 dias após a produção.

\begin{tabular}{c|c|c|c|}
\hline \multicolumn{1}{c}{ Análise } & Tempo (em dias) & Formulação 1 & Formulação 2 \\
\hline Aspecto & 0 & Oleoso; homogêneo & Consistente; Homogêneo \\
& 30 dias & Levemente amarelada & Branco \\
\hline Cor & 0 & --- & Característico \\
& 30 dias & Característico & -- \\
\hline Odor & 0 & --- & 4,48 \\
\hline pH & 30 dias & 5,0 & -- \\
\hline Densidade & 0 & --- & 2,0 \\
\hline
\end{tabular}

Fonte: Autores.

Figura 4 -Formulação 1.

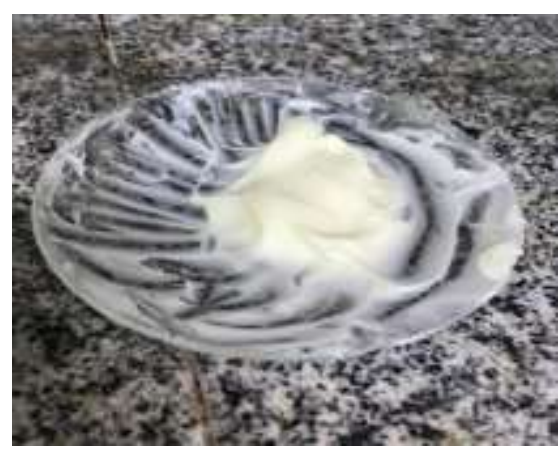

Fonte: Autores.

Figura 5: Formulação 2.

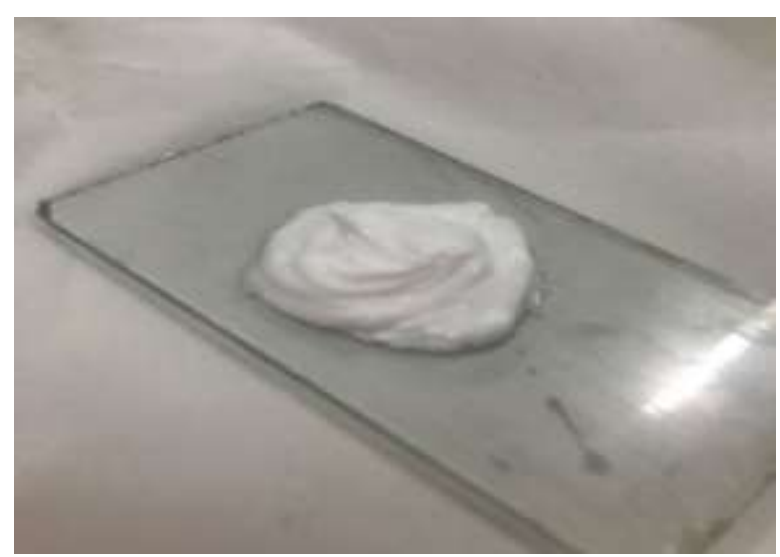

Fonte: Autores. 


\section{Discussão}

Visto que o Brasil é o $4^{\circ}$ maior exportador de óleos essenciais do mundo, e atrelado à riqueza em biodiversidade existente no país, evidencia-se a importância da tecnologia enzimática como alternativa de aplicação para a indústria farmacêutica (Almeida, et. al., 2020; Santos, 2008). Além disso, o emprego desta técnica tem destaque pela sustentabilidade e, sobretudo, pela diminuição de tempo/custo, uma vez as biomassas mais aproveitadas na FES são os resíduos agroindustriais inutilizados e descartados, que atuam como base sólida e ofertam nutrientes para o crescimento de microrganismos (Reis, 2015; Santos, 2008).

No presente estudo, utilizando-se de $30 \mathrm{~g}$ da matéria vegetal, comparando a amostra com a adição do extrato multienzimáticos bruto e o branco, atingiu-se um aumento na massa do óleo de alecrim de 83,24\% (Tabela 2). Esse resultado se confrontado com a literatura consultada certifica que o aumento de massa, rendimento e teor do óleo essencial em pretensão é alcançado. Apesar de não terem sido realizados testes de análise quanto à composição majoritária do produto final, fundamentada na bibliografia estudada, não há alterações significativas que impliquem na ação/efeito do óleo essencial.

Santos (2008) em seu estudo realizou a aplicação de enzimas produzidas por Trichoderma reesei e Aspergillus niger em laboratório com o intuito de extrair os óleos essenciais das espécies Melampodium divaricatum e Mentha spicata; Obtendo um resultado significativo, com um aumento de $60 \%$ da produção de óleo por $M$. divaricatum e 55\% para a $M$. spicata, quando comparado com a extração sem aplicação enzimática, o que demonstra a eficácia das enzimas utilizadas. No trabalho de Reis (2015) que também utilizou da aplicação enzimática, produzidas desta vez por Aspergillus niger e aplicadas na extração do óleo essencial de Mentha arvensis, o autor atingiu um aumento da massa de óleo extraído de 194\%, além de constatar que o pré-tratamento com enzimas manteve o componente majoritário do óleo íntegro e conservado, demonstrando que a utilização dos extratos multienzimáticos é um procedimento viável. Duncke (2015) que realizou um estudo preliminar do uso de enzima na extração de óleo essencial de Capim Limão (Cymbopogon citratus) constatou um acréscimo de $71 \%$ no teor de óleo obtido (Tabela 6).

Assim, ainda que existam diversas variáveis envolvidas em todas as etapas (Figura 1) e processos (cultivo dos fungos filamentosos, FES, pré-tratamento enzimático e hidrodestilação) é perceptível a conformidade em relação ao aumento no rendimento do óleo essencial.

As formulações desenvolvidas apresentaram-se como alternativas viáveis de cosméticos, dado que a incorporação do óleo foi concluída com êxito, sem comprometimento da estabilidade dos cremes. Ambas as fórmulas foram selecionadas considerando a capacidade de miscigenação com um ativo oleoso, neste caso, o óleo essencial de alecrim (Tabela 3 e 4). Diante das análises físico-químicas, as duas composições demonstraram comportamento semelhante em relação a pH e densidade, assim como os ensaios organoléticos, que revelaram a qualidade e estabilidade das fórmulas (Tabela 5).

Tabela 6. Comparação dos resultados obtidos em outros trabalhos que também empregaram o pré-tratamento enzimático.

\begin{tabular}{lcccc}
\hline TRATAMENTO & $\begin{array}{c}\text { Óleo essencial de } \\
\text { alecrim extraído pela } \\
\text { aplicação de enzimas } \\
\text { produzidas por fungos } \\
\text { filamentosos* }\end{array}$ & $\begin{array}{c}\text { Extração de óleo } \\
\text { essencial de capim-limão } \\
\text { com aplicação de enzima } \\
\text { Celluclast a } 0,1 \%{ }^{* 1}\end{array}$ & $\begin{array}{c}\text { Caldo enzimático } \\
\text { produzido em laboratório } \\
\text { e aplicado na extração de } \\
\text { óleo essencial de } \\
\text { Melampodium }\end{array}$ & $\begin{array}{c}\text { Caldo multienzimatico } \\
\text { produzido por } \\
\text { Aspergillus niger e } \\
\text { aplicadas na extração do } \\
\text { óleo essencial de } \\
\text { Mentha arvensis, } \\
\text { extraído por } \\
\text { hidrodestilação*3 } \\
\text { spicata por }\end{array}$ \\
\hline $\begin{array}{l}\text { \% obtenção de óleo } \\
\text { essencial }\end{array}$ & $\mathbf{8 1 , 4 5 \%}$ & $\mathbf{7 1 \%}$ & $\mathbf{6 0 \%}$ & $\mathbf{1 9 4 \%}$ \\
\hline
\end{tabular}

*1Duncke, 2018; *2Santos, 2008; *3Reis, 2015. Fonte: Autores. 


\section{Conclusão}

Os resultados desta pesquisa evidenciaram que a partir da aplicação dos extratos multienzimáticos (EMB) alcançou-se uma otimização de $83,24 \%$ na extração do óleo de alecrim, que obteve também os parâmetros físicos, químicos e organolépticos desejados e necessários de acordo com a legislação vigente. Além de que, desenvolveu-se uma formulação tópica cosmética com a adição do óleo essencial extraído que também atingiu as especificações e os padrões de qualidade exigidos pela Farmacopeia Brasileira.

No entanto, esse estudo preliminar sugere a necessidade de pesquisas futuras com enfoque em testes mais específicos e quantitativos para maior apuração da potencialização enzimática na extração de óleos essenciais, além de que sejam também realizados outros ensaios na perspectiva de averiguar a qualidade de cosméticos produzidos a partir dos mesmos.

\section{Referências}

Agência Nacional de Vigilância Sanitária. (2005). Guia de estabilidade de produtos cosméticos. Editora Anvisa.

Cassini, J. (2015). Utilização de enzimas para a obtenção de óleos essenciais e cumarinas da casca de Citrus latifolia Tanaka.

da Silva, R. T., Bersaneti, G. T., Chideroli, R. T., de Pádua Pereira, U., Lonni, A. A. S. G., Bigotto, B. G., \& Celligoi, M. A. P. C. (2020). Propriedades biológicas da levana de Bacillus subtilis natto e do óleo essencial de canela para aplicação em formulações cosmecêuticas. Brazilian Journal of Development, 6(5), 23009-23024.

de Almeida, J. C., De Almeida, P. P., \& Gherardi, S. R. M. Potencial antimicrobiano de óleos essenciais: uma revisão de literatura de 2005 a 2018.

de Fátima Santos, M., Ferrante, M., Gavilanes, ML, \& Carvalho, EEN (2020). Aromaterapia de Rosmarinus officinalis L. (Lamiaceae) em testes in vivo: revisão sistemática. Research, Society and Development, 9 (9), e228996971-e228996971.

de Jesus, J. G., da Silva Lobo, V., da Rosa, M. F., \& Eising, R. (2021). Elaboração de fórmulas farmacêuticas de uso tópico utilizando óleo essencial extraído do capim limão. Brazilian Journal of Development, 7(3), 21800-21815.

dos Santos Reis, N., de Brito, A. R., do Bomfim Costa, L. C., Silva, T. P., da Silva, E. G. P., \& Franco, M. (2015). Aplicação de extrato multienzimático de aspergillus niger na extração de óleos essenciais de mentha arvensis por hidrodestilação.

dos Santos Reis, N., de Santana, NB, de Carvalho Tavares, IM, Lessa, OA, dos Santos, LR, Pereira, NE, ... \& Franco, M. (2020). Extração de enzimas por hidrodestilação em escala de laboratório de óleo essencial de gengibre (Zingiber officinale Roscoe): análises cromatográficas e micromorfológicas. Culturas e produtos industriais , 146, 112210 .

Duncke, J. (2018). Estudo preliminar do uso de enzima na extração de óleo essencial de capim-limão (Cymbopogon citratus) (Bachelor's thesis, Universidade Tecnológica Federal do Paraná).

Farmacopéia Brasileira (2019), 6 a edição. São Paulo.

Martins, R. M., Cortez, L. E. R., \& Felipe, D. F. (2008). < b> Desenvolvimento de Formulações de Uso Tópico Empregando o Óleo Essencial Extraído do Cravo-da-Índia. Saúde e Pesquisa, 1(3), 259-263.

Migoto, J. N. (2018). Produção de creme hidratante a partir de óleo essencial extraído do amendoim Arachis Hypogaea L (Bachelor's thesis, Universidade Tecnológica Federal do Paraná).

Miyaoka, M. F. (2012). Avaliação do potencial dos fungos do gênero Rhizopus spp na produção de substâncias bioativas com ação antioxidante utilizando diferentes substratos.

Oliveira, S., \& Moraes, C. A. P. (2019). Desenvolvimento de uma emulsão o/a associada ao óleo essencial de gerânio (Pelargonium graveolens) e ao óleo essencial de palmarosa (Cymbopogon martinii). Brazilian Journal of natural sciences, 2(3), 127-127.

Pagnoca, S.G.,\& Cardoso, L.E. (2008) Estudo de estabilidade em creme hidratante para as mãos. XII INIC/ VIII EPG - UNIVAP.

Peixoto, J. S. A., da Silva, B. B. M., Lima, L. M. V., de Souza Ferreira, F. E., \& de Medeiros, F. D. rosmarinus officinalis 1.: alecrim, uso popular e científico da atividade terapêutica.

Ribeiro, DS, Melo, DB, Guimarães, AG, \& Velozo, ES (2012). Avaliação do óleo essencial de alecrim (Rosmarinus officinalis L.) como modulador da resistência bacteriana. Semina: Ciências Agrárias, 33 (2), 687-695.

Santos, E. D. (2008). Utilização de enzimas produzidas por Trichoderma reesei e Aspergillus niger na extração de óleos essenciais.

Sarto, M. P. M., \& Junior, G. Z. (2014). Atividade antimicrobiana de óleos essenciais. Revista UNINGÁ Review, 20(1).

Silva, L. C., Carvalhedo, L. F., Vieira, J. P. C., de Carvalho Silva, L. A., Monteiro, O. S., \& do Carmo, L. H. A. (2015). Delineamento de formulações cosméticas com óleo essencial de Lippia gracilis Schum (Alecrim-deTabuleiro) de origem amazônica. Revista de Ciências Farmacêuticas Básica e Aplicada, 36(2). 
Research, Society and Development, v. 10, n. 16, e293101623771, 2021

(CC BY 4.0) | ISSN 2525-3409 | DOI: http://dx.doi.org/10.33448/rsd-v10i16.23771

Silva, L. I., Silva, G. F., \& Albuquerque, P. M. (2015). Desenvolvimento e avaliação de um fitocosmético utilizando extratos e óleo essencial de Aniba canelilla. Blucher Chemical Engineering Proceedings, 1(2), 14546-14553.

Silva, F. V. F., Santos, M. C., Neiva, L. D. B., Oliveira, M. A. C., de Sousa Leal, B., dos Santos Moreira, F. A., ... \& Neto, M. P. L. (2019). Desenvolvimento e controle de qualidade de um gel-creme antiacneico a base do óleo da Copaífera officinalis L.(copaíba). Revista Eletrônica Acervo Saúde, (30), e974-e974.

Steffens, A. H. (2010). Estudo da composição química dos óleos essenciais obtidos por destilação por arraste a vapor em escala laboratorial e industrial (Master's thesis, Pontifícia Universidade Católica do Rio Grande do Sul). 